\title{
Correlation between thyroid autoantibodies and the risk of thyroid papillary carcinoma
}

\author{
Xuyang Peng ${ }^{1 \#}$, Xi Zhu ${ }^{2 \# \wedge}$, Feng Cheng ${ }^{2}$, Bin Zhou ${ }^{2}$, Xiaohua Zhu ${ }^{3}$, Lei Zhu ${ }^{2}$ \\ ${ }^{1}$ Department of Cardiothoracic Surgery, Lishui People's Hospital, Lishui 323000, China; ${ }^{2}$ Department of Thyroid and Breast Surgery, ${ }^{3}$ Department \\ of Gynaecology and Obstetrics, Lishui Hospital of Zhejiang University, Lishui 323000, China \\ Contributions: (I) Conception and design: X Peng, X Zhu; (II) Administrative support: L Zhu; (III) Provision of study materials: F Cheng, B Zhou; \\ (IV) Collection and assembly of data: XH Zhu; (V) Data analysis and interpretation: X Zhu, X Peng; (VI) Manuscript writing: All authors; (VII) Final \\ approval of manuscript: All authors. \\ "These authors contributed equally to this work. \\ Correspondence to: Lei Zhu, MD. Department of Thyroid and Breast Surgery, Lishui Hospital of Zhejiang University, 289 Kuocang Road, Lishui \\ 323000, China. Email: Dr_zlei@163.com.
}

Background To investigate the correlation of thyroglobulin antibody (TgAb) and thyroid peroxidase antibody (TPOAb) with the risk of papillary thyroid carcinoma (PTC).

Methods: The clinical data of 322 patients with pathologically confirmed thyroid nodules who underwent surgical treatment in Lishui Hospital of Zhejiang University from January 2018 to December 2019 were enrolled in this study. The enrolled patients were divided into a benign nodule group and a PTC group according their pathological results. Comparison was drawn based around the difference of thyroid autoantibody distribution between groups and its correlation with the risk of PTC.

Results: The positive rate of TgAb in the PTC group was significantly higher than that in the benign nodule group $(\mathrm{P}<0.05)$. The incidence of PTC was significantly higher in TgAb positive patients in the presence of negative TPOAb $(\mathrm{P}<0.05)$. Further regression analysis revealed positive $\mathrm{TgAb}$ to be a risk factor of $\mathrm{PTC}(\mathrm{OR}=3.097, \mathrm{P}<0.05)$, while age $\geq 55$ years old $(\mathrm{OR}=0.188, \mathrm{P}<0.05)$ and nodule diameter $\geq 10 \mathrm{~mm}$ $(\mathrm{OR}=0.064, \mathrm{P}<0.05)$ reduced the risk of PTC. Simultaneously, positive TgAb was also a risk factor for PTC in females $(\mathrm{OR}=3.532, \mathrm{P}<0.05)$, but not in males $(\mathrm{P}>0.05)$. The risk of $\mathrm{PTC}$ in females was not associated with further increase in the titer of $\mathrm{TgAb}$.

Conclusions: TgAb may be associated with an increased risk of PTC in females, but there is no clear correlation between the risk of PTC and higher antibody titer in these patients.

Keywords: Thyroglobulin antibody (TgAb); thyroid peroxidase antibody (TPOAb); papillary thyroid carcinoma (PTC)

Submitted Feb 29, 2020. Accepted for publication Jun 04, 2020.

doi: $10.21037 / g s-20-445$

View this article at: http://dx.doi.org/10.21037/gs-20-445

\section{Introduction}

The incidence of thyroid carcinoma, one of the most common malignancies of the endocrine system, has increased rapidly over recent decades (1). Thyroid carcinoma can be categorized by pathology into papillary carcinoma, follicular carcinoma, medullary carcinoma, and undifferentiated carcinoma. Comprising about $80-90 \%$ of the incidence of thyroid malignancies, papillary thyroid carcinoma (PTC) $(2,3)$ is the main component of thyroid carcinoma.

\footnotetext{
$\wedge$ ORCID: 0000-0002-8661-5449
} 
Patients with PTC who receive early diagnosis and surgical intervention have a 5 -year survival rate of $90 \%$ (4). However, despite PTC patients being able to expect a relatively good prognosis, the postoperative recurrence rate is still $30 \%(5,6)$. Recent studies have uncovered a close association between chronic inflammation and tumor occurrence and development. The inflammatory microenvironment in tumor development can induce cell mutation and thus accelerate tumor cell proliferation $(7,8)$. Although the mechanism is still unclear, the molecular mechanisms of PTC occurrence include the PI3K/Akt pathway and the RAS/RET/ERK pathway, which are triggered in both PTC and autoimmune thyroid diseases $(9,10)$. Similarly, immunohistological markers of PTC can be found in tissues with autoimmune thyroid disease, such as P63 (11) and cytokeratin 19 (12). Furthermore, autoimmune thyroid disease, which is mainly characterized by an increase in the level of thyroid autoantibody, is the most frequently occurring form of chronic inflammation of the thyroid. Of the various types of thyroid antibodies, thyroglobulin antibody (TgAb) and thyroid peroxidase antibody (TPOAb) are the most common. Studies have shown an association between $\mathrm{TgAb}$ and an increased risk of PTC, regardless of the presence of autoimmune thyroid disease (9). However, these results have been inconsistent (10). In this study, a retrospective study was carried out of cases who underwent thyroid surgery during a two-year period; their clinical data were collected and the correlation between thyroid autoantibodies and the risk of PTC was investigated. At the same time, the gender difference was analyzed.

We present the following article/case in accordance with the STROBE reporting checklist (available at http://dx.doi. org/10.21037/gs-20-445).

\section{Methods}

\section{Study participants}

The clinical data of 322 patients who underwent firsttime thyroid surgery in Lishui Hospital of Zhejiang University between January 2018 and December 2019 were retrospectively analyzed. Prior to the operation, to facilitate the measurement of serum TgAb, TPOAb, and thyroidstimulating hormone (TSH), the patients received thyroid gland and neck examination by color Doppler ultrasound. The diagnosis of PTC or benign nodules was confirmed by routine postoperative histopathological examination.
Patients who met any of the following criteria were excluded from the study: previous medical history of thyroid surgery, thyroid radiation, hyperthyroidism, hypothyroidism, subacute thyroiditis, or Hashimoto's thyroiditis; or had received oral thyroid treatment before operation. This study was approved by the Ethics Committee of Lishui Hospital of Zhejiang University, and all of the participants signed an informed consent form prior to their inclusion in the experiment.

\section{Study methods}

The clinical data of each enrolled patient including age, gender, the largest nodule diameter, thyroid autoantibodies ( $\mathrm{TgAb}$ and TPOAb), and postoperative pathological results were recorded. TgAb and TPOAb were detected by Abbott i2 000 automatic chemiluminescent immunoanalyzer. For $\mathrm{TgAb},<4$ and $\geq 4 \mathrm{U} / \mathrm{mL}$ were negative and positive respectively, and for TPOAb, $<9$ and $\geq 9 \mathrm{U} / \mathrm{mL}$ were negative and positive, respectively. The pathological diagnosis criteria of Hashimoto's thyroiditis were: decreased size in the thyroid follicular epithelium; reduced colloid, lymphocyte, and plasma cell infiltrates in different degrees; and the formation of the lymphoid follicle and germinal center. According to the pathological results, PTC was divided into microcarcinoma (maximum diameter $<1 \mathrm{~cm}$ ) and non-microcarcinoma (maximum diameter $\geq 1 \mathrm{~cm}$ ) (12). The trial was conducted in accordance with the Declaration of Helsinki (as revised in 2013).

\section{Statistical analysis}

SPSS Statistics 23.0 (Chicago, SPSS, IL, USA) was used for statistical analysis. Measurement data of non-normal distribution were expressed in quartile intervals and compared using the Mann-Whitney U-test. Counting data were expressed in $\mathrm{n}(\%)$ and analyzed by Chi-square test. Logistic regression was used for multivariate regression analysis. Statistically significant difference was represented by $\mathrm{P}<0.05$.

\section{Results}

\section{Comparison of the positive rate of $\operatorname{Tg} A$ b between the benign nodule group and the PTC group}

Of the enrolled 322 patients, 61 were male $(18.9 \%)$ and 261 were female $(81.1 \%)$. The median age was 49 years old 
Table 1 The distribution of anti-thyroid antibodies in patients with benign nodules and papillary thyroid cancer

\begin{tabular}{|c|c|c|c|c|c|c|c|c|c|}
\hline Group & $\mathrm{n}$ & $\begin{array}{c}\text { Male } \\
{[n(\%)]}\end{array}$ & Age (year) & $\begin{array}{l}\text { Nodule } \\
\text { diameter } \\
(\mathrm{mm})\end{array}$ & $\begin{array}{l}\text { Combined with } \\
\text { Hashimoto's } \\
\text { thyroiditis [n (\%)] }\end{array}$ & $\begin{array}{c}\mathrm{TgAb}^{+} \\
\mathrm{TPOAb}^{-} \\
\text {[n (\%)] }\end{array}$ & $\begin{array}{c}\mathrm{TgAb}^{-} \\
\mathrm{TPOAb}^{+} \\
{[\mathrm{n}(\%)]}\end{array}$ & $\begin{array}{c}\operatorname{TgAb}^{+} \\
\mathrm{TPOAb}^{+} \\
{[\mathrm{n}(\%)]}\end{array}$ & $\begin{array}{c}\mathrm{TgAb}^{-} \\
\mathrm{TPOAb}^{-} \\
{[\mathrm{n}(\%)]}\end{array}$ \\
\hline \multicolumn{10}{|c|}{ Papillary thyroid cancer } \\
\hline Total & 231 & $42(18.2)$ & $46[38-53]^{\star}$ & $6[5-10]^{*}$ & $75(32.5)^{\star}$ & $33(14.3)^{\star}$ & $7(3.0)$ & $101(43.7)^{\star}$ & $90(39.0)^{*}$ \\
\hline$\geq 10 \mathrm{~mm}$ & 69 & $16(23.2)$ & $46(39.5-53)^{*}$ & $13(11-17.5)^{*}$ & $23(33.3)^{\star}$ & $8(11.6)$ & $1(1.4)$ & $34(49.3)^{\star}$ & $26(37.7)^{\star}$ \\
\hline
\end{tabular}

Vs. benign nodule, ${ }^{*}, \mathrm{P}<0.05$. TgAb, thyroglobulin antibody; TPOAb, thyroid peroxidase antibody.

Table 2 The distribution of anti-thyroid antibodies in patients with benign nodules and papillary thyroid cancer of different genders

\begin{tabular}{|c|c|c|c|c|c|c|c|c|c|c|}
\hline Group & \multicolumn{5}{|c|}{ Female } & \multicolumn{5}{|c|}{ Male } \\
\hline Benign nodule & 72 & $4(5.6)$ & $1(1.4)$ & $20(27.8)$ & $47(65.3)$ & 19 & $1(5.3)$ & $1(5.3)$ & $4(21.1)$ & $13(68.4)$ \\
\hline \multicolumn{11}{|c|}{ Papillary thyroid cancer } \\
\hline$<10 \mathrm{~mm}$ & 136 & $21(15.4)^{\star}$ & $4(2.9)$ & $60(44.1)^{*}$ & $51(37.5)^{\star}$ & 26 & $4(15.4)$ & $2(7.7)$ & 7 (26.9) & $13(50.0)$ \\
\hline$\geq 10 \mathrm{~mm}$ & 53 & $8(15.1)$ & $1(1.9)$ & $27(50.9)^{*}$ & $17(32.1)^{*}$ & 16 & $0(0.0)$ & $0(0.0)$ & $7(43.8)$ & 9 (56.3) \\
\hline
\end{tabular}

Vs. benign nodule, ${ }^{*}, \mathrm{P}<0.05$. TgAb, thyroglobulin antibody; TPOAb, thyroid peroxidase antibody.

(range, 40-54 years). There were 91 cases of benign nodules and 231 cases of PTC. The positive rate of TgAb was significantly higher in the PTC group (58.0\%) compared with the benign nodule group $(31.9 \%)(\mathrm{P}<0.05$, Table 1$)$. Meanwhile, the positive rate of $\mathrm{TgAb}$ was $56.8 \%$ and $60.9 \%$ in patients with microcarcinoma and non-microcarcinoma, respectively, and the difference was statistically significant. $(\mathrm{P}<0.05)$. Following the exclusion of 75 patients with Hashimoto's thyroiditis, the positive rate of TgAb in the PTC group was still significantly higher than that in the benign nodule group $(\mathrm{P}<0.05)$.

\section{Dependency of the TPOAb and $T g A b$ positive rates in patients with benign and malignant nodules}

In patients with negative TPOAb, the prevalence of PTC was $86.8 \%$ and $60.0 \%$ in patients with positive and negative TgAb, respectively, with statistically significant difference $(\mathrm{P}<0.05)$. However, in TPOAb positive patients, a statistically significant difference did not exist $(\mathrm{P}>0.05)$, with a prevalence of PTC in patients with positive and negative $\mathrm{TgAb}$ of $80.8 \%$ and $77.8 \%$, respectively. In addition, there was no statistically significant difference between the prevalence of $\mathrm{PTC}$ in patients with positive and negative $\mathrm{TgAb}$, regardless of the positive state of $\mathrm{TgAb}(\mathrm{P}>0.05)$. Therefore, the incidence of PTC in TgAb positive patients was be much higher when TPOAb was negative.

\section{Gender differences in the relationship between $T g A b$ and PTC}

In female patients, the positive rate of $\mathrm{TgAb}$ was $61.4 \%$ in the PTC group and $33.3 \%$ in the benign nodule group $(\mathrm{P}<0.05$, Table 2). In male patients, the positive rate of TgAb was $42.9 \%$ and $26.3 \%$ in PTC group and benign nodule group, respectively, and there was no statistically significant difference $(\mathrm{P}>0.05)$. Further regression analysis showed that positive $\mathrm{TgAb}$ was a risk factor of PTC $(\mathrm{OR}=3.097, \mathrm{P}<0.05$, Table 3$)$, while age $\geq 55$ years old $(\mathrm{OR}=0.188, \mathrm{P}<0.05)$, nodule diameter $\geq 10 \mathrm{~mm}(\mathrm{OR}=0.064$, 
Table 3 Multiple logistic regression analysis of risk factors of papillary thyroid carcinoma [OR (95\% CI)]

\begin{tabular}{lccc}
\hline Group & Total & Female & Male \\
\hline Age $\geq 55$ y & $0.188(0.094-0.372)^{*}$ & $0.228(0.106-0.490)^{*}$ & $0.071(0.012-0.407)$ \\
Nodule diameter $\geq 10 \mathrm{~mm}$ & $0.064(0.031-0.132)^{*}$ & $0.070(0.033-0.150)^{*}$ & $0.024(0.002-0.264)^{\star}$ \\
$\mathrm{TgAb}^{+}$ & $3.097(1.148-8.355)^{*}$ & $3.532(1.219-10.233)^{\star}$ & $2.073(0.077-55.705)$ \\
$\mathrm{TPOAb}^{+}$ & $0.888(0.321-2.459)$ & $0.858(0.289-2.550)$ & $1.071(0.038-30.041)$ \\
\hline
\end{tabular}

*, $\mathrm{P}<0.05$. TgAb, thyroglobulin antibody; TPOAb, thyroid peroxidase antibody.

Table 4 Regression analysis of TgAb titer and thyroid papillary carcinoma risk in women

\begin{tabular}{lc}
\hline Group & OR $(95 \% \mathrm{Cl})$ \\
\hline Normal range group & $4.065(1.952-8.466)^{*}$ \\
$60-240 \mathrm{IU} / \mathrm{L}$ & $2.630(1.064-6.500)^{*}$ \\
$>240 \mathrm{IU} / \mathrm{L}$ & $2.192(0.821-5.854)$ \\
\hline
\end{tabular}

*, $\mathrm{P}<0.05 . \mathrm{TgAb}$, thyroglobulin antibody.

$\mathrm{P}<0.05)$ could reduce the risk of PTC. Simultaneously, positive TgAb was also a risk factor for $\mathrm{PTC}$ in females $(\mathrm{OR}=3.532, \mathrm{P}<0.05)$, but not in males $(\mathrm{P}>0.05)$.

\section{Correlation between $\mathrm{TgAb}$ titer and risk of female PTC}

Female patients were further divided into four subgroups based on different $\mathrm{TgAb}$ titers (unmeasurable: $\mathrm{TgAb}<4 \mathrm{IU} / \mathrm{L}$, normal range, 4-60; 60-240; and >240 IU/L). Regression analysis was conducted with the unmeasurable group serving as the control. The results showed that the risk of PTC $(\mathrm{OR}=4.065, \mathrm{P}<0.05$, Table 4$)$ and $60-240 \mathrm{IU} / \mathrm{L}(\mathrm{OR}=2.630$, $\mathrm{P}<0.05)$ were remarkably higher in the normal range group than in the control group. Meanwhile, there was no obvious increase in the risk of PTC in the $>240$ IU/L group $(\mathrm{OR}=2.192, \mathrm{P}>0.05)$. This could suggest that the risk of PTC did not increase with the increase of $\mathrm{TgAb}$ titer in females with nodules.

\section{Discussion}

Thyroid carcinoma has one of the fastest-growing incidences of any malignancy, with a consistent increase observed each year. Preliminarily determining the nature of thyroid nodules is of clinical importance to facilitating subsequent differentiation between benign and malignant lesions and providing a possible reference for the selection of adequate treatment planning at the later stage.
TgAb and TPOAb are the markers of autoimmune thyroid diseases. TgAb is an antibody produced by thyroglobulin ( $\mathrm{Tg}$ ) in thyroid follicles, mainly immunoglobin $\mathrm{G}$, after entering the blood which has high immune specificity. It can combine with $\mathrm{Tg}$ and transporter cells. It can combine with $\mathrm{Tg}$ and transporter cells, activate natural killer cells (NK) through the interaction between $\mathrm{Fc}$ receptors, and bind with antibodies to attack target cells, thus leading to the destruction of thyroid follicular cells. TgAb is mainly secreted by B lymphocytes in the thyroid gland, mainly exists in the thyroid gland. The accumulation of TgAb to a certain concentration in the thyroid gland might not only lead to increased TG decomposition, but might also hydrolyze other proteins unrelated to $\mathrm{Tg}$, resulting in enhanced systemic proteolysis and tissue damage (11). TPOAb is an antibody produced by thyroid peroxidase (TPO) on the apical membrane of thyroid follicular epithelium, which stimulates the body to produce when the thyroid tissue is diseased, and can cause immune damage to the thyroid. TPOAb can also cause direct damage to thyroid cells via complement-dependent cytotoxicity (CDC).

Chronic inflammation is an important factor in tumor development $(7,8)$. Some studies have documented that autoimmune thyroiditis can cause cytokeratin, $\mathrm{p} 63$, and RET gene rearrangement and thus promote tumor formation (13-16). Thus, their relationship with differentiated thyroid cancer has also been a concern for researchers. Several researchers believe that the increased level of $\mathrm{TgAb}$ is not only an indicator of autoimmune disease, but also a predictor of thyroid carcinoma $(17,18)$. In the past, the diagnosis of Hashimoto's thyroiditis was made mainly based on laboratory and clinical diagnosis, which could result in missed diagnosis for some patients with negative autoantibody. In our study, however, postoperative pathology was adopted as the gold standard by which to evaluate the presence of Hashimoto's thyroiditis, highlighting the reliability of our results. 
In the comparison between the distribution of thyroid autoantibody in the benign nodule and PTC groups, the positive rate of TgAb in the PTC group was found to be significantly higher than that in benign nodule group $(\mathrm{P}<0.05)$. Moreover, the incidence of PTC was significantly higher in TgAb-positive patients when TPOAb was negative $(\mathrm{P}<0.05)$. Further regression analysis revealed $\mathrm{TgAb}$ as a risk factor of PTC $(\mathrm{OR}=3.097, \mathrm{P}<0.05)$, although TPOAb level was not suggested to be correlated with PTC; these findings are inconsistent with the research of Rebuffat et al. (19) and Rho et al. (20). The reason for this difference might be related to the different binding sites of the two autoantibodies, suggesting that the relationship between TgAb and the risk of PTC could be related to the tumorigenic mechanism, rather than the course of inflammation itself. Although a causal genetic relationship has not been established to date, RET/PTC rearrangement may be associated with tgab-ptc tumor transformation (21). In addition, it may also be attributed to the bias caused by the small sample size. Concurrently, it was discovered that age $\geq 55$ years old $(\mathrm{OR}=0.188, \mathrm{P}<0.05)$, nodule diameter $\geq 10 \mathrm{~mm}(\mathrm{OR}=0.064, \mathrm{P}<0.05)$ could reduce the risk of PTC, which is consistent with a previous report (22) that found young patients to have a higher risk of thyroid cancer. However, our study indicated that the maximum nodule diameter was negatively correlated with the risk of PTC, which is in conflict with the accepted results. The reason for this may be explained by the increased detection rate of thyroid nodules. Meanwhile, in female patients, positive TgAb was also a risk factor for PTC $(\mathrm{OR}=3.532, \mathrm{P}<0.05)$, which may be related to the higher incidence rate of autoimmune thyroiditis in females. This may be related to the high incidence of autoimmune thyroiditis in females and the selection bias caused by the small sample size of males in this study. The risk of PTC in the normal range group $(\mathrm{OR}=4.065, \mathrm{P}<0.05$, Table 4$)$ and in the $60-240 \mathrm{IU} / \mathrm{L}$ group $(\mathrm{OR}=2.630, \mathrm{P}<0.05)$ was significantly higher than that in the control group, but there was no clear increase in the risk of PTC in the $>240 \mathrm{IU} / \mathrm{L}$ group $(\mathrm{OR}=2.192, \mathrm{P}>0.05)$. This suggests that the risk of PTC did not increase along with the increase of TgAb titer in females with nodules. The reason is not very clear, the author thinks that it may be related to the immune damage of TPOAb on thyroid follicular cells, but it has nothing to do with the severity of the damage.

In summary, our study analyzed the relationship between two thyroid autoantibodies and the risk of PTC with pathological results of Hashimoto's thyroiditis serving as the gold standard, taking into account age, maximum diameter of nodule, gender, and other related factors. TgAb may be associated with an increased risk of PTC in females, but there is no clear correlation between the risk of PTC and higher antibody titer in these patients. This provides a certain differential value for PTC diagnosis. In future, prospective experimental studies based on larger sample sizes are needed to confirm our findings.

\section{Acknowledgments}

Funding: This paper was supported by Lishui Science and Technology Bureau Self-raised Public Welfare Technology Application Project in 2019 (Fund No. 2019SJZC44).

\section{Footnote}

Reporting Checklist: The authors have completed the STROBE reporting checklist. Available at http://dx.doi. org/10.21037/gs-20-445

Data Sharing Statement: Available at http://dx.doi. org/10.21037/gs-20-445

Conflicts of Interest: All authors have completed the ICMJE uniform disclosure form (available at http://dx.doi. org/10.21037/gs-20-445). Drs. XP, XZ, BZ, XHZ, LZ report grants from Lishui Science and Technology Bureau, during the conduct of the study; Dr. FC has no conflicts of interest to declare.

Ethical Statement: The authors are accountable for all aspects of the work in ensuring that questions related to the accuracy or integrity of any part of the work are appropriately investigated and resolved. The trial was conducted in accordance with the Declaration of Helsinki (as revised in 2013). This study was approved by the Ethics Committee of Lishui Hospital of Zhejiang University (No. 2018-82), and all of the participants signed an informed consent form prior to their inclusion in the experiment.

Open Access Statement: This is an Open Access article distributed in accordance with the Creative Commons Attribution-NonCommercial-NoDerivs 4.0 International License (CC BY-NC-ND 4.0), which permits the noncommercial replication and distribution of the article with the strict proviso that no changes or edits are made and the original work is properly cited (including links to both the 
formal publication through the relevant DOI and the license). See: https://creativecommons.org/licenses/by-nc-nd/4.0/.

\section{References}

1. Ferrari SM, Fallahi P, Ruffilli I, et al. Molecular testing in the diagnosis of differentiated thyroid carcinomas. Gland Surg 2018;7:S19-29.

2. Nix P, Nicolaides A, Coatesworth AP. Thyroid cancer review 1: presentation and investigation of thyroid cancer. Int J Clin Pract 2005;59:1340-4.

3. Shaha AR, Tuttle RM. Thyroid cancer staging and genomics. Ann Transl Med 2019;7:S49.

4. Zimmerman D, Hay ID, Gough IR, et al. Papillary thyroid carcinoma in children and adults: long-term follow-up of 1039 patients conservatively treated at one institution during three decades. Surgery 1988;104:1157-66.

5. Rossing M, Nygaard B, Nielsen FC, et al. High prevalence of papillary thyroid microcarcinoma in danish patients: a prospective study of 854 consecutive patients with a cold thyroid nodule undergoing fine-needle aspiration. Eur Thyroid J 2012;1:110-7.

6. Cheng SP, Lee JJ, Lin JL, et al. Characterization of thyroid nodules using the proposed thyroid imaging reporting and data system (TI-RADS). Head Neck 2013;35:541-7.

7. Balkwill F, Mantovani A. Inflammation and cancer: back to Virchow? Lancet 2001;357:539-45.

8. Allavena P, Garlanda C, Borrello MG, et al. Pathways connecting inflammation and cancer. Curr Opin Genet Dev 2008;18:3-10.

9. Ding D, Liu Z, Zhao L, et al. Role of PI3K/Akt pathway in Benzidine-induced proliferation in SV-40 immortalized human uroepithelial cell. Transl Cancer Res 2019;8:1301-10.

10. Kang DY, Kim KH, Kim JM, et al. High prevalence of RET, RAS, and ERK expression in Hashimoto's thyroiditis and in papillary thyroid carcinoma in the Korean population. Thyroid 2007;17:1031-8.

11. Unger P, Ewart M, Wang BY, et al. Expression of p63 in papillary thyroid carcinoma and in Hashimoto's thyroiditis: a pathobiologic link? Hum Pathol 2003;34:764-9.

Cite this article as: Peng X, Zhu X, Cheng F, Zhou B, Zhu X, Zhu L. Correlation between thyroid autoantibodies and the risk of thyroid papillary carcinoma. Gland Surg 2020;9(4):950-955. doi: 10.21037 /gs-20-445
12. Arif S, Blanes A, Diaz-Cano SJ. Hashimoto's thyroiditis shares features with early papillary thyroid carcinoma. Histopathology 2002;41:357-62.

13. Kim ES, Lim DJ, Baek KH, et al. Thyroglobulin antibody is associated with increased cancer risk in thyroid nodules. Thyroid 2010;20:885-91.

14. Rago T, Di Coscio G, Ugolini C, et al. Clinical features of thyroid autoimmunity are associated with thyroiditis on histology and are not predictive of malignancy in 570 patients with indeterminate nodules on cytology who had a thyroidectomy. Clin Endocrinol (Oxf) 2007;67:363-9.

15. Miyauchi A. Clinical Trials of Active Surveillance of Papillary Microcarcinoma of the Thyroid. World J Surg 2016;40:516-22.

16. Fiore E, Vitti P. Serum TSH and risk of papillary thyroid cancer in nodular thyroid disease. J Clin Endocrinol Metab 2012;97:1134-45.

17. Muller S, Senne M, Kirschniak A, et al. Impact of surgical resection extension on outcome for primary welldifferentiated thyroid cancer-a retrospective analysis. World J Surg Oncol 2017;15:190.

18. Spencer C, Fatemi S. Thyroglobulin antibody (TgAb) methods - Strengths, pitfalls and clinical utility for monitoring TgAb-positive patients with differentiated thyroid cancer. Best Pract Res Clin Endocrinol Metab 2013;27:701-12.

19. Rebuffat SA, Morin M, Nguyen B, et al. Human recombinant anti-thyroperoxidase autoantibodies: in vitro cytotoxic activity on papillary thyroid cancer expressing TPO. Br J Cancer 2010;102:852-61.

20. Rho MH, Kim DW, Hong HP, et al. Diagnostic value of antithyroid peroxidase antibody for incidental autoimmune thyroiditis based on histopathologic results. Endocrine 2012;42:647-52.

21. Grani G, Calvanese A, Carbotta G, et al. Thyroid autoimmunity and risk of malignancy in thyroid nodules submitted to fine-needle aspiration cytology. Head Neck 2015;37:260-4.

22. Guarino V, Castellone MD, Avilla E, Melillo RM. Thyroid cancer and inflammation. Mol Cell Endocrinol 2010;321:94-102. 